\title{
A LUTA DO MST EM MATO GROSSO DO SUL: ANÁLISE CONJUNTURAL DAS MANIFESTAÇÕES DO CAMPO
}

\author{
Recebido em 30/01/2020, aprovado em 6/03/2020 \\ 10.30612/mvt.v6i11.10973 \\ Lara Dalperio Buscioli²
}

\begin{abstract}
RESUMO: A questão agrária no Brasil é permeada por diversos conflitos territoriais das quais as ocupações de terras e as manifestações realizadas pelos movimentos socioterritoriais (camponeses, indígenas, quilombolas etc.) tem se tornado a principal forma de conquista pela terra/território. Fatos evidenciados no estado do Mato Grosso do Sul (MS), que em todo o seu histórico de formação é marcado pelas disputas entre fazendeiros, agronegócio, Estado e movimentos socioterritoriais. Estas açóes têm gerado modificaçóes territoriais expressivas na área rural do referido estado, principalmente com a inserção de empresas de capital estrangeiro, configurando um elemento analítico importante. Assim, este estudo se propóe elucidar as atuaçóes do Movimento dos Trabalhadores Rurais Sem Terra em MS, através das manifestaçóes do campo entre 2000 e 2018, buscando compreender em sua totalidade a dimensionalidade da questão agrária. Isto foi possível pelas metodologias de levantamento bibliográfico, entrevista e sistematização dos dados quantitativos do DATALUTA.
\end{abstract}

Palavras-chave: Manifestaçóes do Campo. Movimento dos Trabalhadores Rurais Sem Terra. Mato Grosso do Sul.

\section{THE MST FIGHT IN MATO GROSSO DO SUL: CONJUNCTURAL ANALYSIS OF MANIFESTATIONS OF THE FIELD}

ABSTRACT: The agrarian issue in Brazil is permeated by several territorial conflicts, of which land occupations and demonstrations carried out by socio-territorial movements (peasants, indigenous people, quilombolas, etc.) have become the main form of conquest over land/territory. Facts evidenced in the state of Mato Grosso do Sul (MS), which throughout its history of formation is marked by disputes between farmers, agribusiness, the State and socio- territorial movements.

2 Doutoranda em Geografia na Universidade Estadual Paulista "Júlio de Mesquita Filho" (UNESP) em Presidente Prudente (SP) na área de Geografia Agrária com orientaçáo do Prof. Dr. Bernardo Mançano Fernandes e bolsista da Fundação de Amparo à Pesquisa do Estado de São Paulo (FAPESP). Atua desde 2010 no "Núcleo de Estudos, Pesquisas e Projetos de Reforma Agrária" (NERA) e membro da Rede DATALUTA. Bem como, atuou como professora conferencista no curso de Turismo da UNESP no campus de Rosana e como professora substituta em Geografia no Instituto Federal de Educaçáo, Ciência e Tecnologia de Mato Grosso do Sul (IFMS). E-mail: lara.dalperio@gmail.com 
These actions have generated significant territorial changes in the rural area of that state, mainly with the insertion of companies with foreign capital, configuring an important analytical element. Thus, this study aims to elucidate the actions of the Movimento dos Trabalhadores Rurais Sem Terra in MS, through the manifestations of the field between 2000 and 2018, seeking to fully understand the dimensionality of the agrarian issue. This was made possible by bibliographic survey methodologies, interviews and systematization of quantitative data from DATALUTA.

Keywords: Manifestations of the Field. Movimento dos Trabalhadores Rurais Sem Terra. Mato Grosso do Sul.

\section{LA MST LUCHA EN MATO GROSSO DO SUL: ANÁLISIS DE LA CONJUNCIÓN DE LAS MANIFESTACIONES DEL CAMPO}

RESUMEN: La cuestión agraria en Brasil está permeada por varios conflictos territoriales, de los cuales las ocupaciones de tierras y las manifestaciones llevadas a cabo por movimientos socio-territoriales (campesinos, indígenas, quilombolas, etc.) se han convertido en la principal forma de conquista de la tierra / territorio. Hechos evidenciados en el estado de Mato Grosso do Sul (MS), que a lo largo de su historia de formación está marcado por disputas entre agricultores, agronegocios, el Estado y movimientos socio-territoriales. Estas acciones han generado cambios territoriales significativos en el área rural de ese estado, principalmente con la inserción de empresas con capital extranjero, configurando un elemento analítico importante. Por lo tanto, este estudio tiene como objetivo dilucidar las acciones del Movimento dos Trabalhadores Rurais Sem Terra en MS, a través de las manifestaciones del campo entre 2000 y 2018, buscando comprender completamente la dimensionalidad del problema agrario. Esto fue posible gracias a metodologías de encuestas bibliográficas, entrevista y sistematización de datos cuantitativos de DATALUTA.

Palavras Clave: Manifestaciones del campo. Movimento dos Trabalhadores Rurais Sem Terra. Mato Grosso do Sul.

\section{INTRODUÇÃO}

Historicamente o estado do Mato Grosso do Sul tem se destacado pelos conflitos territoriais e resistências diante de frentes de ocupação, presença de grandes propriedades rurais, incorporação do capital estrangeiro relacionado à internacionalização no mercado, aliado à pecuária, soja e cana-de-açúcar (re)criando assim, resistências como as atuaçôes em ocupaçôes de terras dos movimentos socioterritoriais.

Desde o início do processo de ocupação do Mato Grosso do Sul, ocorreram conflitos e resistências pelo território, que foi ocupado por duas frentes de colonização que datam nos anos iniciais do século XX, com a vinda de imigrantes do estado do Rio Grande do Sul que desenvolveram a pecuária e o plantio de ervas, e outra frente de meados das décadas de 1950/1960, no reverso da "cuesta" da Serra de Amambai, próxima aos limites do estado do Paraná e São Paulo onde havia 
predominância das florestas (AVELINO JUNIOR, 2008).

Moreno (2005) aponta que a geopolítica do uso e ocupação do solo do estado do Mato Grosso do Sul pelo grande capital, bem como sua tecnificação do trabalho e organização produtiva, é uma herança com impactos sentidos ainda na atualidade.

Esses impactos são de níveis social, econômico e ambiental, como o devido ao uso intensivo de agrotóxicos ou modificação do mercado de terras no estado, com estratégias de compra e arrendamento de terras de empresas/grupos impedindo a reforma agrária através das ocupaçôes de terras e dificultando a produção agroecológica ou orgânica nos assentamentos.

As empresas/grupos que fazem parte deste cenário estratégico são: Adecoagro; ADM, Arauna; Biosev; BR Food; Bunge; Central Energética Vicentina; Cerona; Fibria; Galtere; George Soros, InternationalPaper; Louis Dreyfus; Monsanto; MSU Agro; Odebrecht; Parkia Participaçóes; Raízen; Safi Brasil; SLC Agrícola; Usina São Fernando; Clean Energy; Grupo Biourja e Grupo Poet, com os mais diversos capitais Argentina, Reino Unido, Emirados Árabes, EUA, França, Holanda, Itália, Japão etc. (DATALUTA, 2016).

Neste contexto histórico de ocupação do MS e de avanço do agronegócio nacional e estrangeiro que surge o Movimento dos Trabalhadores Rurais Sem Terra (MST), para realizar açóes de resistências no referido estado. Assim, o MST desde a sua origem na década de 1980 tem ligaçáo com o território, abrangendo suas lutas por melhores condiçóes de vida nos acampamentos e assentamentos, buscando saúde, educação, produção de qualidades entre outras.

A Comissão Pastoral da Terra teve um papel importante para o MST em MS, pois foi por meio dela que o Movimento conseguiu se organizar em trabalhos de base e reunióes, permitindo e fortalecendo a sua consolidação. Assim, as conquistas que o MST tem travado no estado ao longo dos anos estão vinculadas com as suas lutas e resistências que partem das ocupaçóes de terras como importantes instrumentos da conquista do território camponês e das manifestaçóes que se realizam em áreas urbanas, mas com destaque e desdobramentos para as causas do campo.

As ocupaçóes originam os assentamentos rurais entendidos neste trabalho como territórios camponeses, ou seja, espaços de lutas, resistências e esperança. Estes territórios camponeses vêm sofrendo com os impactos causados com a territorialização do agronegócio nacional e estrangeiro dentro deles e em seu entorno. Neste sentido, a luta contra este processo ocorre de forma intensa no Mato Grosso do Sul, buscando contrapor ideias e o modelo de produção pautado nas commodities com a produção camponesa que tem lógicas distintas.

Como um fortalecimento para essas lutas e agregação de resistências temos as manifestaçôes do campo que, na conjuntura de luta, se consolidaram como instrumentos importantes e de visibilidade da luta camponesa em outros espaços e territórios para além do rural. Elas se diferenciam das ocupaçôes de terras devido ao caráter territorial e estrutural.

Diante disso, o presente artigo busca analisar as manifestaçóes do campo realizadas entre os anos de 2000 e 2018, apresentado uma tendência das principais reivindicações e formas de ações realizadas no estado do Mato Grosso do Sul pelo Movimento dos Trabalhadores Rurais Sem Terra.

Para melhor compreensão da temática apresentaremos no próximo subtópico quais foram os procedimentos metodológicos utilizados para a realizaçáo deste artigo. Seguindo apresentaremos os principais apontamentos do surgimento do Movimento dos Trabalhadores Rurais Sem Terra no estado do Mato Grosso do Sul para então, compreendermos as atuaçôes dele na forma de manifestação como elemento histórico sua luta e resistência.

Por fim, apresentaremos as consideraçóes finais elaboradas a partir do desenvolvimento da pesquisa e suas bases bibliográficas que permitiram a partir da aplicação das metodologias a campo 


\section{e laboratorial a sistematização teórico-conceitual da temática.}

\section{PROCEDIMENTOS METODOLÓGICOS EXECUTADOS}

Os procedimentos metodológicos da pesquisa foram realizados no sentido de produzirmos informaçóes quantitativas e qualitativas que deram subsídios para suprirmos os objetivos do artigo. Desta forma, o dividimos em duas partes para melhor compreensão e sistematização do estudo: $1^{\circ}$ ) Produçóes de informaçôes qualitativas com a aplicação de entrevista e pesquisa bibliográfica; 2º Produçôes de informaçôes quantitativas com a sistematização de dados do DATALUTA.

Em relação à primeira parte realizaremos pesquisas bibliográficas sobre os temas que envolvem a pesquisa, como exemplo: a questão agrária, ocupaçóes de terras, manifestaçóes do campo, campesinato, lutas camponesas, agricultura capitalista, agronegócio entre outros temas. Sendo realizada por meio de leituras de livros, teses, dissertaçóes, artigos científicos ejornais de escala nacional, estadual e regional compondo uma gama de informaçôes qualitativas importantes para a compreensão e análise da temática.

$\mathrm{Na}$ realização da entrevista partimos dos estudos realizados por Colognese e Melo (1998), que as compreendem como um processo de interaçáo social entre o pesquisador e o entrevistado, com a finalidade de obtençáo de informaçóes, a partir de uma conversa interessada e orientada pelo entrevistador.

Para suprir nossos objetivos, partimos da entrevista com caráter formal e semi- estruturada, ou seja, embora apresentem um roteiro, podemos ter liberdade de adicionar perguntas conforme necessidade e a fala do entrevistado, podendo interferir no momento da entrevista (COLOGNESE; MELO, 1998).

Em relação à segunda parte, produções de informações quantitativas com a sistematização de dados do DATALUTA que reúne elementos analíticos da questão agrária brasileira. O DATALUTA é composto pelas seguintes categorias analíticas: movimentos socioterritoriais e suas duas formas de atuação: ocupaçôes de terras e manifestaçôes do campo, estrutura fundiária, assentamentos rurais e estrangeirização de terras. Esses dados são confrontados a partir de diferentes fontes como a Comissão Pastoral da Terra (CPT), a Ouvidoria Agrária Nacional, o Instituto de Terras do Estado de São Paulo, o Instituto Nacional de Colonização e Reforma Agrária (INCRA), Rede DATALUTA etc.

Para este artigo utilizaremos as categorias de movimentos socioterritoriais e manifestaçóes do campo, para os dados do estado de Mato Grosso do Sul, que serão armazenados em planilhas do programa Microsoft Excel, onde geraremos bases para as elaborações de tabelas, gráficos e quadros, que farão parte do trabalho. Os dados para a elaboração dos mapas serão tabulados no Excel, gerados no programa Philcarto e para a arte final utilizaremos o programa CorelDraw, suprindo assim, os objetivos de mapear a questão agrária/conflitos no campo no referido estado.

O estudo sobre as manifestaçóes nos permitem classifica-las de acordo com suas tipologias formas de ação, devido à grande diversidade das açóes. No DATALUTA (2019), identificamos as tipologias de: acampamento, audiência pública, bloqueio, caminhada, marcha, ocupação, ocupação de agência bancária, ocupação de espaço privado, ocupação de espaço público, formação de acampamento, greve de fome/sede, liberação de praça de pedágio, ocupação de prédio público, ocupação de prédio privado, ocupação de prédio público/privado, ocupação praça de pedágio, outros, , romaria, saque, temática (água, terra, questôes ambientais, indígenas, política agrícola) e vigília.

Cabe ressaltar que parte deste artigo são realizaçôes desenvolvidas e composta na dissertação de mestrado intitulada "Impactos e Resistências no Processo de Estrangeirização de Terras em Rio 
Brilhante (MS): O Caso dos Projetos de Assentamentos Federais São Judas, Margarida Alves, Silvio Rodrigues e do Território Indígena Laranjeira Nanderu”, sob orientação de Bernardo Mançano Fernandes e fomento da Fundação de Amparo à Pesquisa do Estado de São Paulo (FAPESP), com a atualização dos dados quantitativos e novas análises, que qualificarão e darão seguimento basilar à futuras pesquisas de análise geográfica sobre a questão agrária no estado do Mato Grosso do Sul.

\section{APONTAMENTOS SOBRE O MST EM MATO GROSSO DO SUL: ELEMENTOS HISTÓRICOS PARA COMPREENDERMOS A CONJUNTURA ATUAL}

Para iniciarmos os debates sobre a resistência camponesas por meio das manifestaçóes do campo e ocupaçôes de terras realizadas pelo Movimento dos Trabalhadores Rurais Sem Terra, partiremos da análise da origem do Movimento ${ }^{3}$ em Mato Grosso do Sul, que teve como principal aliada a CPT em meados da década de 1980.

Para isso, apresentaremos os primeiros conflitos camponeses pela e na terra no referido estado que foram iniciados na década de 1970, devido às irregularidades em contratos de arrendamentos e reivindicaçóes de algumas áreas, conforme apontaram os estudos de Fabrini (1996).

Com esta situação os movimentos camponeses, de trabalhadores rurais e de sindicalistas, iniciaram as suas primeiras açôes de resistência frente ao latifúndio, organizando-se para construir os trabalhos de base que seguiriam nas próximas décadas, sendo determinantes para a obtenção de seus territórios no caso o território camponês, por meio das ocupaçóes de terras no referido estado.

Segundo Fabrini (1996), a história de resistência no estado se inicia principalmente com as lutas em Naviraí e em Glória de Dourados, onde no primeiro município o movimento foi de arrendatários com destaque para a participaçáo da CPT e do Sindicato Rural de Naviraí ocupando três fazendas: Entre Rios, Água Doce e Jequitibá. Devido a essa participação os arrendatários, após ganho de causa para permanência na área da fazenda Jequitibá por dois anos devido a irregularidades no contrato, reivindicam a desapropriação tendo forte repressão do fazendeiro e com o acontecimento um fato que mudaria o rumo da organização dos arrendatários, o assassinato do advogado que os defendia.

Esta ação se tornou o marco inicial para a luta dos sem-terras (FABRINI, 1996), pois configurou-se como um elemento repressivo e violento direto aos que lutavam pelo direito ao acesso a terra, culminando na consequência lástima e irreversível que é a morte de um defensor da causa e de todas as açôes até então executadas.

Fernandes (1999) faz uma narrativa importante para compreendermos a trajetória do MST no estado do Mato Grosso do Sul, bem como desta ação descrita por Fabrini (1996) como marco do Movimento:

Desde 1979, nos municípios de Naviraí, Itaquiraí, Taquarussu, Bonito e Glória de Dourados, os latifundiários pararam de arrendar terras, pois as fazendas já estavam formadas. Enquanto formavam as fazendas, derrubando a mata e plantando capim, os camponeses plantavam algodáo e outras culturas, faziam poços e se estabeleciam. Durante muito tempo, com o fim do arrendamento, os camponeses migravam, mas naquele ano resistiram. Algumas das lutas de resistência aconteceram em Naviraí, nas fazendas Entre Rios, Água Doce e

3 Ao escrevermos Movimento com a letra maiúscula, estamos nos referindo ao movimento socioterritorial MST. 
Jequitibá, envolvendo em torno de 240 famílias (FERNANDES, 1999, p. 60).

A respeito da fazenda Jequitibá os acampados ganharam a causa na justiça em meio aos conflitos e ameaças do fazendeiro para permanecerem por mais de um ano, reivindicando a área para reforma agrária. Com isso, o fazendeiro soltou nas lavouras dos camponeses gados para que ela fosse perdida, além de ameaças contra o acampamento que causou na saída de vários camponeses. Com a intervenção do advogado Joaquim das Neves Norte frente a essa situação, gerou um conflito que culminou na sua morte, por meio de um atentado intensificando a situação precária no território (FERNANDES, 1999).

Esses conflitos foram aumentando na medida em que o governo intervia na questão agrária do estado, por meio do Projeto Guatambu que tinha como objetivo dar assistência para as famílias camponesas. Mas, segundo o autor este projeto não funcionou e ocasionou alguns conflitos materializados na ocupação da fazenda Baunilha em Itaquiraí com 800 camponeses que não estavam com uma organização consolidada, assim o Governo juntamente com a Federação dos Trabalhadores da Agricultura convenceram os camponeses a saírem da área, uns ficaram acampados nas margens de uma rodovia onde a polícia militar cercou com arame farpado para absolutamente ninguém entrar, depois sofreram repressão, foram despejadas e transferidas para outro estado:

Coagidas, isoladas, sem apoio, pouco a pouco foram abandonando oacampamento. Restou 68 famílias que sobreviveram trabalhando de bóia- fria. O governo transferiu essas famílias para uma área de cerrado, no município de Cassilândia, na divisa com o estado de Goiás, distante mil quilômetros de Itaquiraí. Quando chegaram à área, perceberam que, mais uma vez, haviam sido enganados. $\mathrm{O}$ Incra havia lhes prometido que a área era boa, mas encontraram areia e estavam a 90 quilômetros da cidade mais próxima. Também nessa área a polícia manteve o cerco e impediu que a CPT realizasse reunióes com os trabalhadores. Durante 4 meses permaneceram alojadas em um barracão até serem transferidas para os lotes, onde não tinha água, só areia e pedra A primeira colheita foi um fracasso. Para não morrerem de fome, passaram a trabalhar como diaristas em áreas próximas, onde a agricultura era mecanizada. A falta de água, a terra arenosa, a fome, as doenças, a distância e a falta de comunicação agravaram a situação das famílias. A CPT realizou uma campanha de alimentos para ajudar as famílias e passou a denunciar o descaso do governo para com os trabalhadores assentados. Encaminhou um dossiê ao governador, pedindo uma soluçáo para o caso. O governo propôs a transferência das famílias para o norte do Mato Grosso. As famílias tentam negociar a transferência para o sul do Mato Grosso do Sul, mas diante da miséria em que se encontravam e da intransigência do governo, aceitaram a mudança para o município de Colider, a um mil e quinhentos quilômetros de onde se encontravam (FERNANDES, 1999, p. 61).

Muitas dessas famílias morreram com o contágio de doenças e/ou abandonaram a luta devido à falta de perspectiva de vida com a difícil situação de saírem do estado do Mato Grosso do Sul para serem assentados sem assistência em outro estado. Mesmo com a ajuda da CPT, que se tornou um elemento primordial de apoio, na fortificação do trabalho de base ou em campanhas para a arrecadação de alimentos, os governos conseguiram retardar a luta dos camponeses.

Segundo Fabrini (1996), a CPT teve um papel importante na luta e resistência do MST no 
estado do Mato Grosso do Sul, principalmente com sua origem realizando vários encontros intermunicipais na região da Grande Dourados, dando base para o surgimento do Movimento. Esta história de luta do MST, também está relacionada com os estados da região Sul do Brasil e de São Paulo, um dos fundadores foi Geraldo Garcia, contribuindo para a criação dos setores organizacionais do Movimento (ALMEIDA, 2003).

O militante Celso em entrevista confirma tais fatos:

Em 1984, quando surgiu o Movimento, o Movimento começou a fazer um trabalho de base nas comunidades e aí à gente foi convidado, a minha família, na verdade, foi convidada, os meus pais foram convidados, mas eles não deram muita importância ou não deram nada de importância. E aí a gente fazia parte do ciclo da juventude, através das pastorais da juventude e onde a gente foi incentivado a participar das reunióes, para ouvir qual que era a ideia então (Celso em entrevista ao autor, 2015).

Ele continua...

Então a gente participou de três ou quatro reuniōes, isso em 1984, já final de 1984 e aí houve toda uma mobilização, através do MST, para trabalhar na perspectiva das ocupaçôes de terra. Isso em 25 de maio de 1985, a gente foi para a ocupação. E aí os meus pais não quiseram ir, não quiseram nem participar das reunióes e eu, estimulado, animado, criei a resistência em casa e fui para a ocupação (Celso em entrevista ao autor, 2015).

Nas palavras de Celso, vemos a importância dos primeiros trabalhos de base e das ocupaçóes de terras para dar identidade e amplitude de mobilização territorial para o Movimento. Este trabalho de base foi expressivo na luta do MST no estado, principalmente para a formação das ocupaçôes que precederam os acampamentos organizando suas açôes no seu interior para contribuição da resistência e consolidação de sua territorialização por meio dos assentamentos rurais.

Bernardo Mançano Fernandes (1999) confirma o acontecimento das reuniôes e da organizaçáo dos camponeses para realizar as ocupaçóes e acampamentos como formas de resistências diante da também ajuda/contribuição da Comissão Pastoral da Terra:

Em 1981, as famílias sem-terra realizavam reunióes em 20 municípios. Diversas lutas aconteceram e foram formados acampamentos como forma de resistência. No fim de 1982 foi realizado um encontro em Taquarussu, onde os sem-terra discutiam as formas de apoio e as perspectivas de luta. Avaliam que ficar enviando abaixo-assinado por meio de sindicatos não traz soluçáo para os seus problemas. Elaboram um documento em nome do Movimento Sem Terra do Mato Grosso do Sul e encaminham ao governo, reivindicando o assentamento imediato. Não conseguiram nenhum tipo de acordo: só promessas. Esperar do governo alguma atitude com relação a situação das famílias sem-terra era morrer na estrada. Decidiram sobreviver e começaram a organizar uma ocupação (FERNANDES, 1999, p. 62). 
Esta ocupaçáo, citada pelo autor, fortificou e consolidou a luta do MST pela terra no MS e refere-se a sua primeira ocupação conjunta com a CPT que era responsável pela organização interna do acampamento, conforme nos relata Silva (2004): A área ocupada foi a Gleba Santa Idalina, localizada no município de Ivinhema/MS. Esta ocupação também foi marcada pela violência e pelos conflitos entre os sem-terra, os latifundiários e o Estado, representando pelo entáo governo Wilson Barbosa Martins, do PMDB (SILVA, 2004, p. 38).

Segundo Silva (2004), este latifúndio tinha 18 mil hectares pertencentes à Sociedade de Melhoramentos e Colonização (SOMECO) e quando os camponeses a ocuparam tinham oito mil famílias, que buscavam a conquista deste território em 1984. Ela teve suma importância para mostrar as questóes que envolviam o campo sul-matogrossense, resultando na criação do território camponês Padroeira do Brasil no município de Nioaque.

Segundo Fernandes (1999) o processo para a realização desta ocupação teve vários sujeitos como: os sem terras, paraguaios, camponeses, arrendatários, posseiros e ribeirinhos. Inicialmente, teve grande repercussão por meio dos trabalhos de base e das informaçóes chegadas até o INCRA, polícia civil e a Federação dos Trabalhadores na Agricultura tentando impedir a ação, gerando grandes desafios para a ocupação, pois eles teriam que atravessar o rio Guiraí, assim foi decidido construir uma passarela:

Durante os trajetos até a fazenda Santa Idalina aconteceram vários incidentes. Em Mundo Novo, a Polícia Militar tentou impedir a saída de um comboio e prender alguns trabalhadores. Sem sucesso, os policiais dirigiram- se à uma fazenda no município Japoră, ao sul de Mundo Novo, certos que seria ocupada. Mas, os caminhôes vão em direção ao norte, para Ivinhema. O encontro dos comboios aconteceu na cidade de Sete Placas, mais de 20 caminhóes. Outros se perderam ou estavam atrasados. Alguns foram barrados pela Polícia Rodoviária. O caminhão com os alimentos quebrou e, pior, estava com a maior parte do material para a construção da passarela sobre o rio (FERNANDES, 1999, p. 63).

Mesmo diante desses desafios a luta náo parou, os camponeses chegaram à margem do rio e um homem a nado levou um cabo de aço de uma margem a outra para que iniciasse a travessia também a nado. De manhá, a polícia civil tentou evitar que parte dos camponeses continuassem atravessando, mas foi em vão. Depois da formação do acampamento e de várias discussóes ele foi denominado "Acampamento Venceremos". Nele a polícia fez várias rondas com os carros da SOMECO e o governo tentou negociar objetivando a retirada dos camponeses levando eles para outras localidades, mas não foi aceito devido à história de luta dos sem terras já travada e sem sucesso, como a retirada das famílias para Goiás e a promessa do Governo de enviar alimentos também descumprida (FERNANDES, 1999).

Segundo o autor:

Os sem-terra receberam o apoio de diversas entidades e instituiçóes. Todavia, o governo ordenou a retirada das famílias e Polícia Militar fez o despejo. $\mathrm{Na}$ persistência da luta, acamparam em frente à Catedral de São José. Depois de cinco meses de negociação, os acampados aceitam uma área de 2.500 hectares no município de Nioaque, comprada pelo governo do estado de Mato Grosso do Sul. Seria um assentamento provisório, porque a área máxima para cada família era de 
5 hectares. No final do mês de setembro, todas as famílias foram transferidas para o assentamento que foi denominado Gleba Padroeira do Brasil. Era uma vitória parcial (FERNANDES, 1999, p. 65).

A partir do que foi exposto pelos estudos de Fabrini (1996), Fernandes (1999), Almeida (2003) e Silva (2004), podemos concluir o papel importante das ocupaçóes de terras e dos acampamentos na luta do MST no estado, bem como da CPT na contribuição desta luta e resistência criando territórios camponeses de vida.

Segundo o MST (2009), os representantes do estado do Mato Grosso do Sul tinham participado da fundaçáo do Movimento em Cascavel no estado do Paraná e no $1^{\circ}$. Congresso Nacional, em Curitiba. Apreendendo assim, informaçóes importantes para consolidar as lutas do MST no estado do MS.

Ao final da década de 1980 o MST desvincula-se com a CPT, por meio de rupturas de açóes no âmbito político, com a vinda de duas lideranças nacionais que vieram contribuir com a luta e "consolidar" o MST no estado. Segundo Fabrini (1996), as lideranças eram Darci Domingos Zehn e sua esposa, realizando em 1989 sua primeira ocupação na área da Fazenda Itasul, surgindo posteriormente o assentamento no município de Itaquiraí.

O autor afirma que o MST foi adquirindo autonomia em suas açóes distanciando ainda mais da CPT, assim a partir da década de 1990, eles vão atuar em duas frentes diferentes: a CPT com foco nos assentamentos e o MST atuando de forma ampla preocupando-se desde organização até a luta pela conquista de seu território, assim seu lema era "Terra não se ganha, se conquista" por meio das ocupaçóes. Mas, o Movimento com sua maior experiência de luta observou que só a conquista da terra não era suficiente para suprir com a demanda dos sem terras.

Segundo Fabrini (1996) durante o V Encontro Nacional do MST a palavra de ordem muda, frente às pressôes dos latifundiários:

[...] adotou uma nova palavra de ordem: ocupar, resistir e produzir, resultante do amadurecimento das experiências de luta. A preocupação daí em diante, não seria somente a conquista da terra, mas também organizar a produção para viabilizar os assentamentos de reforma agrária (FABRINI, 1996, p. 88 - grifo do autor).

Fernandes (1999) aponta que esta palavra de ordem, representa de forma incisiva a lógica de luta do MST, dimensionando a reciprocidade nos processos de ocupação e de produçáo, rompendo coma ideia da separação dos sem terras com os com terras, ou seja, os que realizavam as ocupações e os camponeses que já eram assentados. Assim, a única alternativa que o Governo dava era o cumprimento deste lema por parte do MST:

Assim, a ação de ocupar era (e ainda é) necessária para que a os territórios materiais camponeses sejam (re) conquistados frente ao conflito, resistindo e ao ocorrer à materialização dessa luta era necessário produzir. Essa produção não seria voltada para a monocultura e sim, para uma diversificação de alimentos, que seriam mais saudáveis e de boa qualidade que atendesse a sociedade. Assim, toda a sociedade deveria participar nas questóes a respeito da reforma agrária, seja lutando através das manifestaçóes e ocupaçóes ou contribuindo no debate intelectual (DALPERIO, 2012, p. 25). 
No ano de 1995 foi definida pelo Movimento a palavra de ordem: "Reforma agrária: uma luta de todos" e nos anos de 2000 "Reforma agrária: por um Brasil sem latifúndio" (FABRINI, 2008) incorporando que a luta do MST era contra o latifúndio que não cumpria a sua função social.

Segundo Rosemeire Almeida (2003):

[...] o poder das palavras, inclusive as palavras de ordem do Movimento, tais como: "Sem Reforma Agrária não há democracia"; "Ocupar, Resistir e Produzir"; "Reforma Agrária: uma luta de todos"; "Reforma Agrária: por um Brasil sem Latifúndios"; sustenta-se na legitimidade (crença) daquele(s) que a(s) pronuncia(m) e náo no significado semântico ou político (ALMEIDA, 2003, p. 191 - Grifo nosso).

Almeida (2003) diferencia as açôes do MST em relação a outros movimentos socioterritoriais por vários aspectos tais como: ocupações de órgãos públicos para chamar a atenção do Estado e da sociedade para as questóes voltadas ao campo; caminhadas, passeatas e atos públicos objetivando integrar as forças do campo e da cidade; recuperação de alimentos realizada pelo saqueamento de caminhôes que trafegam as rodovias onde o Movimento está acampado; trancamento de rodovias para conseguir alguma ação imediata e por fim, uma das açóes mais importante às ocupaçóes/ acampamentos/despejos na qual eles se articulam para ocupar as áreas devolutas.

As primeiras ações exemplificadas por Almeida (2003) referem-se em nossas análises as manifestaçôes do campo, que são realizadas para chamar a atenção do poder público para as demandas do Movimento ao campo, sejam para os assentados como para os acampados. A segunda é a açáo de resistência direta contra o latifúndio, o agronegócio nas áreas onde eles estão territorializadas, a fim de questionar tais territórios, por meio das ocupaçóes de terras.

Assim, nas páginas que se seguem analisaremos as tendências das açóes do MST no estado do Mato Grosso do Sul a partir das manifestaçóes do campo, que no contexto histórico configuram-se como uma das principais formas de lutas e resistências do Movimento em todo o território brasileiro, especialmente no referido estado.

\section{AS MANIFESTAÇÕES DO CAMPO REALIZADAS PELO MST NO CONTEXTO DE LUTA PELO TERRITÓRIO E POR SUA PERMANÊNCIA}

As manifestaçóes de terras representam no Movimento dos Trabalhadores Rurais Sem Terra uma das principais formas de reivindicação na luta pela conquista do território camponês que dão sentido e caraterização para sua existência em conformidade com suas diferentes práticas de reproduçáo social estabelecida em seu meio, estabelecendo elementos para compreendermos sua permanência nestes territórios.

Segundo Fernandes (1994), as manifestaçôes são importantes na luta, pois dão visibilidades para as questôes voltadas ao campo, ou seja, são atos políticos efetivos de luta. Elas têm caráter políticos e reivindicatórios, partindo de uma coletividade, onde a abrangência de suas açôes, ou seja, a visibilidade pública é marcante (COMERFORD, 1999) e determinante, colocando os temas que envolvem a questáo agrária na pauta de dos Governos e nos centros de mídias impressas e digitais.

Essa coletividade também é mostrada por Pereira (2012), quando realizou um estudo sobre estas açôes e suas tipologias no estado de São Paulo, analisando a espacialização e as principais 
reivindicaçôes dos movimentos em seu contexto de luta, em suas palavras: "as manifestaçôes para os movimentos socioterritoriais são ações que refletem conteúdos estruturais, são organizadas no sentido de evidenciar situaçóes que deveriam ser de interesse social, mas que frequentemente são mascaradas pelo discurso dominante" (PEREIRA, 2012, p. 12-13).

O discurso dominante a respeito das questôes que envolvem o campo brasileiro, traz intencionalidades que acabam por acirrar alguns conflitos, ou seja, o que está em disputa além dos territórios ou mesmo das condiçôes de sobrevivência (infraestruturas) é o entendimento que parte da sociedade terá sobre as reivindicaçôes dos movimentos socioterritoriais na forma de manifestaçóes.

Estes discursos estão embasados em diferentes perspectivas paradigmáticas, das quais o desenvolvimento do campo está atrelado somente com o agronegócio, onde as açóes dos movimentos são vistas como um obstáculo a esse desenvolvimento. Eles estão relacionados aos modelos explicativos baseados em paradigmas que "representam as visóes de mundo, que contém interesses e ideologias, desejos e determinações que se materializam através de políticas públicas nos territórios de acordo com as pretensões das classes sociais" (FERNANDES; WELCH; GONÇALVES, 2014, p. 47).

Os paradigmas que compóem esta realidade são expressos em dois: o Paradigma da Questão Agrária (PQA) e o Paradigma do Capitalismo Agrário (PCA) que buscam em sua essência constituir os parâmetros teórico-ideológicos, pautados na diferenciação dada ao papel do campesinato e, portanto nas propostas de políticas públicas que concorrem entre si dentro da lógica de Estado e de territórios, bem como na compreensão de suas formas de atuaçóes como nas manifestaçóes.

Baseados em Fernandes (2009), entendemos que existem dois tipos de territórios, o imaterial e o material, que são envoltos de três tipologias: primeiro, segundo e terceiro território. O território material é constituído de fixos e fluxos, estabelecendo relaçóes de diferenciaçóes entre Estado, governanças, propriedades, lutas sociais compondo suas ordens: Primeiro território como espaços de governança organizados em diversas escalas; Segundo território como propriedades sendo comunais, privadas, capitalistas, familiares etc.; E terceiro território é o fluxo conexo com territorialidades/ formas de uso dos territórios.

Nesta relação territorial compreendemos que os movimentos socioterritoriais, em especial o MST, questiona por meio das manifestaçôes a legitimidade das atuaçôes dos diferentes sujeitos no primeiro e no segundo território, questiona os tipos de propriedade esuas açóes e fluxos relacionais dentro do terceiro território e suas formas de uso.

O outro tipo de território é o imaterial, também disputado pelo Movimento, da qual o PQA e o PCA estão, bem como suas políticas - que no seio do conflito tem como base está lógica de território. Ele é compreendido a partir da determinação de relaçóes de poder: "pertence ao mundo das ideias, das intencionalidades, que coordena e organiza o mundo das coisas e dos objetos: o mundo material" (FERNANDES, 2009, p. 211).

O PCA parte da tendência da agricultura familiar e do agronegócio, subalternizando e integrando o campesinato ao sistema produtivo (tecnificado e mecanizado) do capital, náo havendo uma questão agrária a ser debatida, bem como a solução dos problemas gerados por seus processos e pelo sistema podem ser resolvidos dentro do capitalismo por meio de políticas que integrem o campesinato/agricultor familiar. (FERNANDES, 2005; FELICIO, 2011; CAMPOS, 2012; BUSCIOLI, 2016). Configurando o primórdio das reivindicaçóes dos movimentos socioterritoriais e, neste caso o MST, conflitando com este modelo explicativo, pois suas lutas nas diversas formas não são consideradas, os modos de vida camponês e suas formas de reprodução também não.

Já no PQA a lógica norteadora é completamente diferente, pois o campesinato se recria no interior do capitalismo e nas suas contradiçôes, buscando formas alternativas de sobrevivência frente 
aos impactos socioterritoriais em seus territórios construindo um novo modelo de desenvolvimento, através de ações de enfrentamento (FERNANDES, 2005; FELICIO, 2011; CAMPOS, 2012; BUSCIOLI, 2016). Nestas açôes de enfrentamento se colocam as manifestaçôes, que a partir da lógica da agricultura familiar/campesinato propõem formas de ter e de se conceber o território, bem como a consolidaçóes de relaçóes em seu terceiro tipo.

Neste sentido, as ações dos movimentos socioterritoriais na forma de manifestaçóes entram nesta conjuntura paradigmática, quando as relacionamos com as formas de reivindicaçóes e resistências ou mesmo pelo próprio ato da sua ação direta. Que nos permitem numa análise mais profunda estudarmos o Estado, o capital e movimentos socioterritoriais no contexto de desenvolvimento de políticas públicas a nível brasileiro e mundial, partindo de diferentes visôes que resultam em distintas formas de uso dos territórios e de apreciação dos sujeitos nas formas de resistências.

Assim, as manifestaçóes caracterizam por meio do questionamento, pois elas são construtoras de espaços políticos de reivindicaçóes e protestos (SILVA, A.; FERNANDES, 2008), com o objetivo de garantir os diretos a terra, água, infraestruturas, cidadanias, ou mesmo, denunciar as violaçóes dos diretos humanos, trabalhistas, ambientais entre outras.

Elas são importantes estratégias de lutas, verdadeiros instrumentos, mostrando a capacidade de articulação e organização que os movimentos socioterritoriais realizam, a fim de despertar a população e aos órgáos públicos os problemas e dificuldades do campo (MOURA, VICTOR, CLEPS JUNIOR, 2012). As consideramos como atos diretos de enfrentamento dos movimentos socioterritoriais e socioespaciais com o objetivo da conquista do território material e imaterial e de formas de permanecer nele dignamente frente as açôes do Estado e de outros sujeitos contrários a tais reivindicações.

Desta forma, torna-se importante analisarmos os dados de manifestaçóes do campo realizados pelos movimentos socioterritoriais no Brasil, especificamente para este artigo o estado do Mato Grosso do Sul como referência territorial para as açóes dos Movimento dos Trabalhadores Rurais Sem Terra, frente ao avanço do capitalismo nestes territórios: "fica caracterizado em Mato Grosso do Sul um processo contraditório de avanço e crescimento do capitalismo no campo, pois, se de um lado temos a concentração da terra, por outro lado surgem os movimentos sociais, na luta pela terra, por sobrevivência e pela cidadania” (AVELINO JÚNIOR, 2008, p. 123).

Nesta luta citada por Avelino Junior (2008), colocamos as manifestaçóes como elementos determinantes na estrutura reivindicatória no estado do Mato Grosso do Sul realizadas pelo MST em diferentes localidades, como podemos observar no mapa 1.

No estado o Movimento realizou 179 manifestaçôes caracterizadas como acampamento, bloqueio, concentração em espaço público, marcha/caminhada, ocupação de agencia bancária, ocupação de prédio privado, ocupação de prédio público, outros, saque e temática, com a participação de 60.165 pessoas.

Destas 20 foram conjuntas com 7.350 pessoas participantes do Movimento de Mulheres Camponesas (MMC), MLRA, Tribunal Popular da Terra-MS 4 , Central Única dos Trabalhadores (CUT), Federação dos Trabalhadores Rurais Agricultores e Agricultoras Familiares do Estado de Mato Grosso do Sul (FETAGRI-MS), Movimento Camponês de Luta pela Reforma Agrária (MCLRA), Central dos Trabalhadores e Trabalhadoras do Brasil (CTB), Movimento Sem-Terra Brasileiro (MSTB) e Via campesina. As principais reivindicaçóes demarcam as temáticas de

4 Coletivo de entidades, e organizaçóes populares e de defesa dos direitos humanos 
infraestrutura, assistência técnica, reforma agrária, demarcação de terras indígenas, contra a Proposta de Emenda à Constituição (PEC) 215, ao Projeto de Lei (PL) 4330 e a redução da maioridade penal (DATALUTA, 2019).

Para este artigo, apresentaremos as análises das manifestaçóes realizadas de caráter exclusivo do Movimento dos Trabalhadores Rurais Sem Terra de forma individual, para compreendermos no contexto histórico como ocorre a luta deste movimento no interior de sua estrutura e reivindicaçóes.

De forma individual, o MST realizou em todo o estado do Mato Grosso do Sul (mapa 1) 159 manifestaçóes do campo com a participação de 52.815 pessoas entre os anos de 2000 e 2018 (DATALUTA, 2019), náo deixando de atuar em nenhum ano, conforme podemos observar no gráfico 1 que apresenta a evolução desta ação.

\section{Gráfico 1: Mato Grosso do Sul - Evolução das manifestações individuais realizadas pelo MST - 2000-2018}

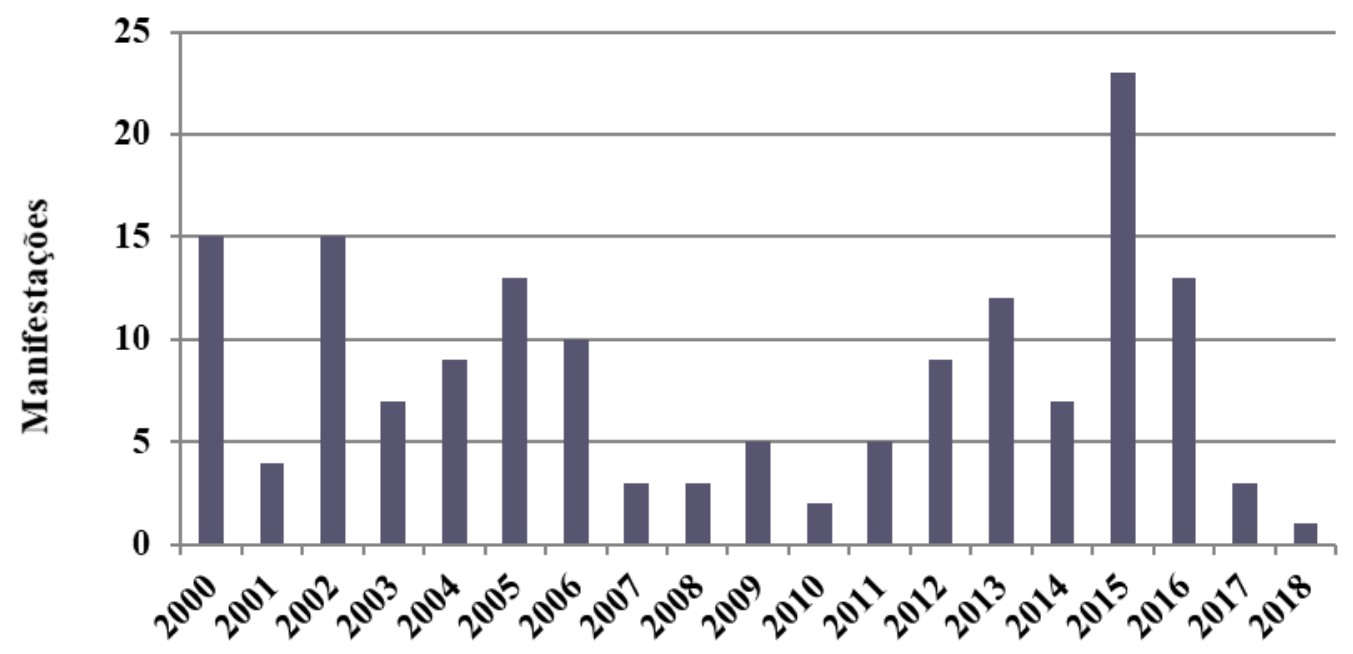

Anos

Fonte: DATALUTA, 2019. Org. Buscioli, 2020

- Manifestações

Podemos observar por meio do gráfico 1 o aumento expressivo da atuação do MST no estado do Mato Grosso do Sul pelas manifestaçóes do campo em 2015, contabilizando 23 açóes. A estes fatos podemos colocar a situação vigente no país naquele momento de pré- golpe com os prenúncios do impeachment da então presidente Dilma Housseff, com um movimento latente de mudanças significativas na conjuntura agrária brasileira com os posicionamentos do Governo com a lentidão da realização de reforma agrária.

Este posicionamento fez com que em 2015 ocorresse uma concentração em espaço público intitulado "Ato em defesa da Democracia e das Reformas Agrária e Política" reunindo 10.000 pessoas em Campo Grande para a reivindicação açôes ligadas a reforma agrária no Brasil e no estado do Mato Grosso do Sul.

Entre os anos de 2003, 2004 e 2005 ocorreu um movimento crescente no cenário das manifestaçôes no estado do Mato Grosso do Sul, momento da qual a inserção do presidente Luiz Inácio Lula da Silva como esperança latente na execução da reforma agrária se colocava como elemento definidor de pressão e reivindicação desta promessa, que ao longo do período vai se perdendo/oscilando frente as correlaçóes de forças desiguais entre as políticas e estruturas paradigmáticas postas 
pelo Governo. Ação que só volta a ganhar forças com o inicio do Governo Dilma, para pressionar em tais realizaçôes como já exposto.

Pós golpe, observamos uma mudança significativa na atuação do MST na forma de manifestação com o aumento da criminalização e repressão dos Governos aos movimentos socioterritoriais com discursos contrários a suas açôes e suas territorialidades. Assim, as açóes tiveram como caráter a luta contra injustiça, violência e reforma agrária, bem como temas emergentes na pauta governamental como a seguridade social e políticas públicas efetivas para a classe trabalhadora e camponesa.

O ano com menor registro das açôes remete-se a 2018, com apenas uma manifestação realizada no município de Itaquiraí com bloqueio da BR-163 em defesa da democracia, contra injustiça e a violência. Evidenciando que no cenário atual a criminalização e legitimação da violência contra os povos que lutam por justiça social será rotineiro.

Dos 79 municípios existentes no estado do Mato Grosso do Sul, o Movimento dos Trabalhadores Rurais Sem Terra esteve presente em 28 localidades principalmente no centro- sul, como podemos observar no mapa 1.

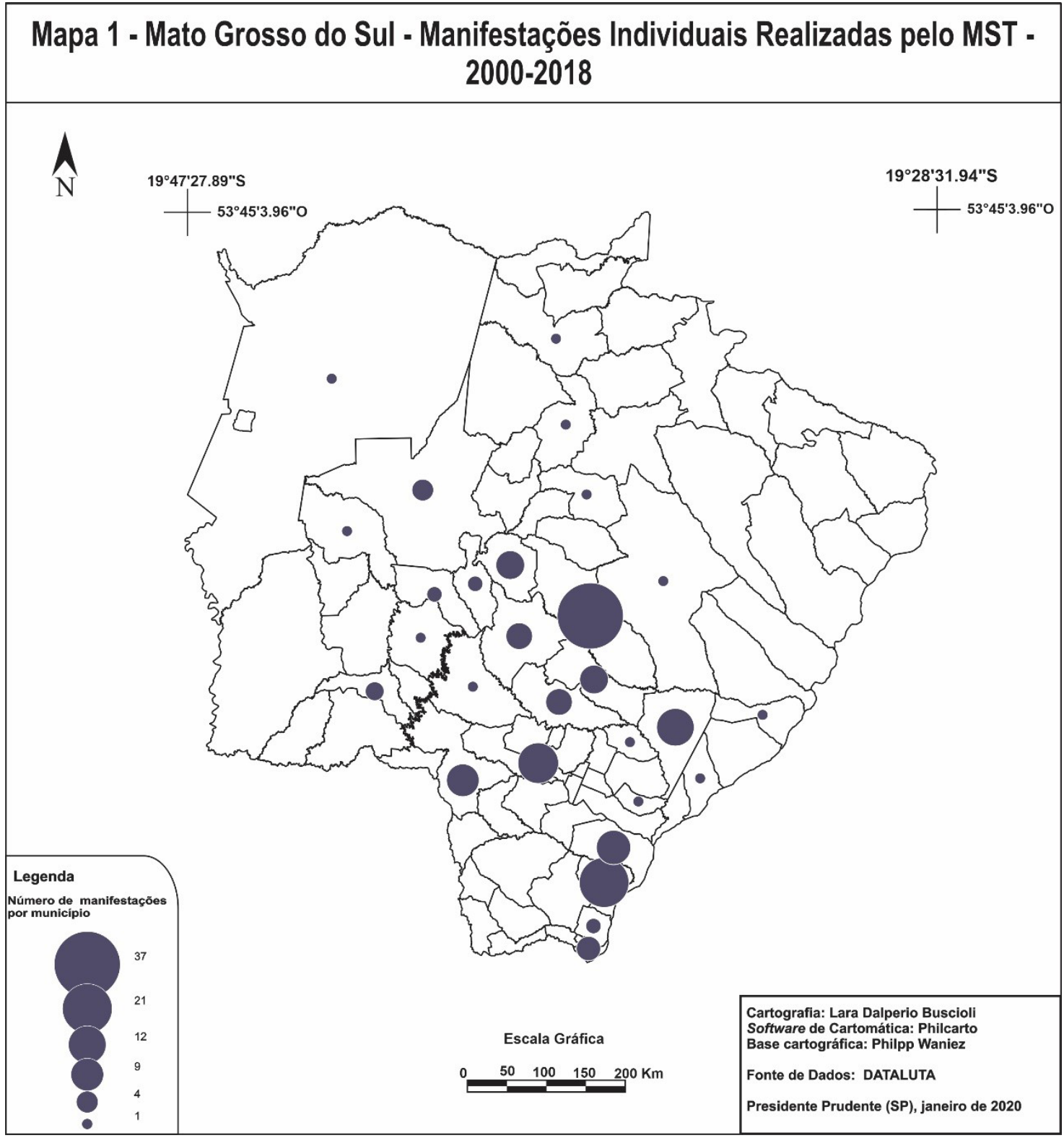


A partir do mapa 1, podemos analisar que as atuaçóes do MST no estado do Mato Grosso do Sul estão presentes de maneira significativas nas regióes e municípios que tem como foco área de poder de decisão, como capital e regionais estabelecidas pelo INCRA e órgão estadual, como por exemplo em Campo Grande com 37 açóes, Itaquiraí com 21 e Dourados com 14, que representam aproximadamente $45 \%$ do total das açóes compondo um histórico de luta do Movimento ou mesmo de conflitos anteriores a ele nestes municípios.

Nessas localidades as principais reivindicaçôes se baseavam em políticas agrícolas, luta pela terra, contra injustiças e violências no campo, pela reforma agrária, contra processo de despejo de famílias acampadas, pela agilidade no processo de execução da reforma agrária no estado entre outros (DATALUTA, 2019).

Numa análise das principais reivindicaçóes no estado do Mato Grosso do Sul temos a centralidade da terra-território para consolidação da existência do MST enquanto movimento socioterritoral. As temáticas abordadas nas reivindicaçôes foram: luta pela realização ou mesmo agilidade no processo da reforma agrária, crédito rural para os assentados, incentivo a pequena produção nos lotes, contra a violência e as conjunturas governamentais do país e do estado, contra a impunidade nos crimes cometidos no campo, contra açôes de despejos, pela permanência de famílias acampadas nas margens de rodovias, em memória do Massacre Eldorado dos Carajás, pela saúde da populaçáo camponesa (DATALUTA, 2019).

Dentre as localidades das açóes temos as manifestaçóes com ocupação do Banco do Brasil, ocupação da Receita Federal, ocupação da Sede do Incra, saques de alimentos para acampamentos, bloqueios de rodovias BR-163 e MS-487, protesto diante do Prédio do Terrasul, protesto na frente da Companhia Nacional de Abastecimento (Conab) em Campo Grande, protesto na frente da Agência dos Correios etc. (DATALUTA, 2019).

A estes tipos de manifestações elencamos as principais tipologias que caracterizam estas açôes ocorridas no estado do Mato Grosso do Sul, pelo Movimento dos Trabalhadores Rurais Sem Terra de forma individual: acampamento, bloqueio, concentração em espaço público, marcha/caminhada, ocupação de agencia bancária, ocupação de prédio privado, ocupação de prédio público, outros, saque e temática, expressadas no gráfico 2 .

\section{Gráfico 2: Mato Grosso do Sul - Distribuição percentual das tipologias de manifestações individuais realizadas pelo MST - 2000-2018}

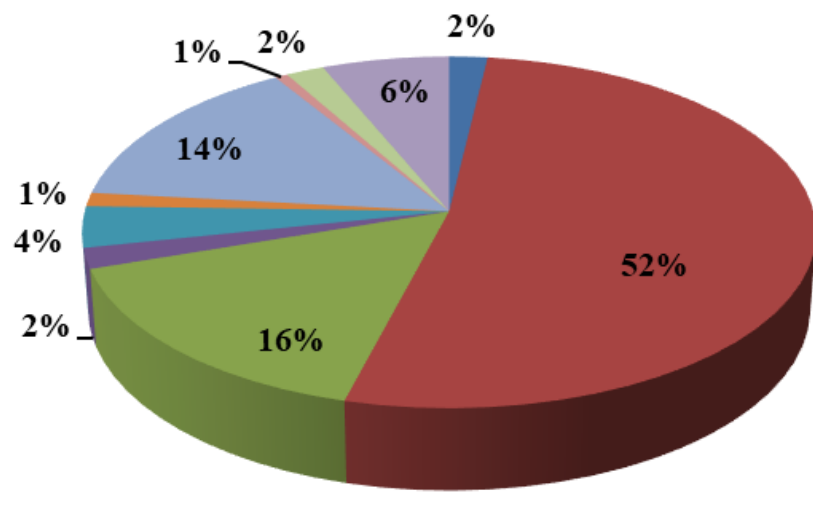

Fonte: DATALUTA, 2019. Org. Buscioli, 2020

\author{
- Acampamento \\ - Bloqueio \\ - Concentração em espaço público \\ - Marcha/Caminhada \\ - Ocupação de agência bancária \\ - Ocupação de prédio privado \\ - Ocupação de prédio público \\ - Outros \\ - Saque \\ - Temática
}


A partir do gráfico 2, podemos observar que os bloqueios representam $52 \%$ do total das manifestaçôes do campo realizadas de forma individual pelo MST no estado do Mato Grosso do Sul, contabilizando 83 açóes com 17.664 pessoas participantes (DATALUTA, 2019). Os bloqueios são realizados principalmente em áreas estratégicas para a sua realização, como entrada e saída da cidade, em áreas onde ocorre o tráfego de caminhóes das usinas, entre outros lugares que causam impactos a nível local/municipal e colocam em pauta na mídia as reivindicaçôes dos movimentos socioterritoriais.

Podemos citar as rodovias estaduais e federais bloqueadas pelo MST: MS-060, MS- 487, BR 163, BR-463 e BR-376 que tinham como objetivo primordial questóes relacionadas ao território em sua dimensão material e imaterial, tais como: luta contra a injustiça e a violência no campo brasileiro, pela realização Reforma Agrária, pelas desapropriaçóes, pelo acesso a linhas de créditos dos camponeses, por infraestruturas em seus territórios (DATALUTA, 2019).

A concentração em espaços públicos é a segunda maior ação de manifestação realizada pelo MST com 16\%. Esta tipologia tem sua origem a partir da falta de informaçóes na hora do registro das açôes dos movimentos socioterritoriais: "podemos citar os registros em nossos bancos de dados que trazem informaçóes do tipo "Protesto", "Ato", "Ato público", "Manifestação", "Manifesto" em determinado espaço ou local (PEREIRA, 2012, p. 55).

Nela foram realizadas 25 açóes compondo os municípios de Dourados, Itaquiraí e Campo Grande com atos e protestos em frente ao Incra, a Conab, a prefeituras e agência dos Correios, reunindo 17.930 pessoas nesta ação.

Ocupação de prédio público é a terceira tipologia mais registrada pelo DATALUTA (2019), contabilizando 23 açôes (14\%) com 8.930 pessoas. Segundo Comerford (1999) essas açôes são localizadas nas sedes dos governos, em locais onde os órgãos competentes para suas questóes/reivindicaçôes ou mesmo em praças. A exemplos ocorridos em MS temos açôes na Receita Federal, na sede do Incra e em prefeituras para reivindicação na solicitação de créditos e incentivos à pequena produção.

Conforme o DATALUTA, a categoria temática está relacionada a encontros e eventos que discutem as temáticas dos movimentos socioterritoriais em suas agendas de luta. Nesta pesquisa, encontramos dez açóes (6\%) com a participação de 2.523 pessoas compondo, por exemplo, o Levante do Campo/Dia do Trabalhador Rural, o Dia Nacional de Luta no Campo/Memória Massacre Eldorado dos Carajás e Jornada Nacional de Luta contra oLatifúndio.

Já as ocupaçôes de agência bancária representam quatro porcento do número total, o que corresponde a seis açóes todas no Banco do Brasil solicitando linhas de créditos, devido aos financiamentos e políticas públicas voltadas apenas para recebimento neste banco. Cabe destacar que participaram 18.000 pessoas nestas ações ocorridas em Itaquiraí, Ponta Porã, Rio Brilhante e Sidrolândia.

Em relação às tipologias, o acampamento consideramos como uma forma de pressionar por longos períodos os governos e órgãos nas estão ligados a questôes que envolvem o campo, que se formam e se configuram como um espaço de enfrentamento e reivindicaçóes. No MS foram realizados três acampamentos com a participação de 1.250 pessoas em Campo Grande no Acampamento no Ginásio Guanandizão, em Mundo Novo no Acampamento diante do Banco do Brasil/Fazenda Indiana/Assentamento Roseli Nunes e em Rio Brilhante no acampamento diante da Prefeitura/ Fazenda Engenho Novo/Assentamento Sílvio Rodrigues.

A caminhada/marcha é um ato de enfretamento nos quais os movimentos socioterritoriais percorrem rodovias e estradas, como ocorridas três vezes no período estudado com 1.100 pessoas. 
"É um ato público em movimento, onde centenas de trabalhadores ocupam as rodovias percorrendo centenas de quilômetros, passando por diversas cidades, conquistando apoio e divulgando a luta pela terra" (FERNANDES, 1994, p. 180). Como por exemplo, as açóes ocorridas em Nova Alvorada do Sul, a Marcha pela Terra e pela Vida/Coluna Dorcelina Folador, em Terenos a Marcha pela Terra e pela Vida/Coluna Geraldo Garcia e em Nova Andradina a Marcha pela Reforma Agrária/Dia Internacional da Mulher.

Os saques foram realizados em Itaquiraí e Jardim contabilizando três açôes com a participação de 1.268 pessoas relacionadas ao Movimento dos Trabalhadores Rurais Sem Terra por questóes relativas à terra. $\mathrm{Na}$ tipologia Ocupação de prédio privado foram realizadas duas açóes com a participação de 350 pessoas reivindicando políticas agrícolas, nas localidades do Laticínio Campestre em Mundo Novo e na Usina De São Francisco em Dourados.

Já a tipologias "outros" são manifestaçôes do campo com outras características diferentes das tipologias apresentadas, mas com uma menor representatividade, como a ocorrida em Terrenos por educação e Reforma Agrária.

Assim, compreendemos que as manifestaçóes do campo são importantes para analisarmos as demandas do campo brasileiro e no caso dos indígenas refletem questóes problemáticas não só de sua desterritorialização, mas de açóes a nível Governo Federal que tem impedido o processo demarcatório de seus territórios ou mesmo colocando na sua pauta questôes sobre violaçóes de seus direitos.

\section{CONSIDERAÇÕES FINAIS}

O MST no estado do Mato Grosso do Sul tem uma grande representatividade nas açóes realizadas por meio do enfrentamento direto ao capital, Estado e agronegócio, seja nacional ou estrangeiro, compondo o que consideramos como parte da conflitualidade exposta desde o processo de criaçáo do referido estado federativo e do Movimento.

Desde os primórdios do seu surgimento o estado traz consigo elementos estruturais da concentração de terras e grilagem, permitindo o questionamento da legitimidade e função social destas terras por meio das ações de ocupaçóes e manifestaçôes, esta última exposta como objeto analítico de atuação do MST.

Das manifestaçóes realizadas pelo Movimento em MS, compreendemos que todas estavam relacionadas a terra/território camponês, o que confere a identidade destes sujeitos, seja no campo de enfrentamento direto ou como nos debates e discussóes realizadas em reunióes e em trabalhos de bases, fortalecendo assim, a sua estrutura organizativa. A análise conjuntural das manifestaçóes, nos permitiu compreender que as açóes oscilaram ao longo dos anos representando os elementos da época, compreendemos que elas se intensificaram em momentos políticos decisivos como início de governos e em locais de grande poder de decisôes como as capitais e em órgãos específicos de reivindicaçóes.

De maneira geral, as reivindicaçóes colocadas nas formas de manifestaçôes compóem elementos definidores do que estamos compreendendo enquanto tipologias de territórios. Ou seja, abarcam a materialidade e a imaterialidade das reivindicaçóes no estado do Mato Grosso do Sul. 


\section{REFERÊNCIAS}

ALMEIDA, Rosemeire Aparecida de. Identidade, distinçáo e territorializaçáo: o processo de (re) criação camponesa no Mato Grosso do Sul. 391f. Tese (Doutorado em Geografia) - Universidade Estadual Paulista, Presidente Prudente, 2003.

ALMEIDA, Rosemeire Aparecida de. A questáo Agrária em Mato Grosso do Sul: uma visão multidisciplinar. 1. ed. Campo Grande: UFMS, 2008.

AVELINO JÚNIOR. Francisco José. A geografia dos conflitos pela terra no Mato Grosso do Sul. In: ALMEIDA, Rosemeire Aparecida de. A questão Agrária em Mato Grosso do Sul: uma visão multidisciplinar. 1. ed. Campo Grande: UFMS, 2008, p. 113-138.

BUSCIOLI, Lara Dalperio. Impactos e Resistências no Processo de Estrangeirizaçáo de Terras em Rio Brilhante (MS): O Caso dos Projetos de Assentamentos Federais São Judas, Margarida Alves, Silvio Rodrigues e do Território Indígena Laranjeira Nanderu. 443 f. Dissertação (Mestrado em Geografia) - Universidade Estadual Paulista. Presidente Prudente, 2016.

CAMPOS, J. F. de S. Leituras dos Territórios Paradigmáticos da Geografia Agrária: Análise dos Grupos de Pesquisa do Estado de São Paulo. 389 f. Tese (Doutorado em Geografia). Universidade Estadual Paulista. Presidente Prudente, 2012.

COMERFORD, John Cunha. Fazendo a luta: sociabilidade, falas, e rituais na construção de organizaçóes camponesas. Rio de Janeiro: Relume Dumará, 1999. Disponível em: < http://nuap.etc.br/homolog/wp-content/uploads/2013/06/fazendo_a_luta.pdf >. Acesso em: 06 dez. 2019.

COLOGNESE, Silvio Antonio; MELO, José Luiz Bica. A Técnica da Entrevista na Pesquisa Social. Porto Alegre: Cadernos de Sociologia, 1998. V. 9, p. 143-159.

DALPERIO, Lara Cardoso. Banco de Dados da Luta pela Terra: atualizaçáo do cadastro dos movimentos socioterritoriais para 2011. 172 f. CNPQ, Presidente Prudente, 2012.

DATALUTA - Banco de Dados da Luta pela Terra, 2016.

DATALUTA - Banco de Dados da Luta pela Terra, 2019.

DATALUTA-MS - Banco de Dados da Luta pela Terra - Mato Grosso do Sul, 2018.

FABRINI, João Edmilson. A posse da terra e o sem terra no sul de Mato Grosso do Sul: o caso Itaquiraí. Corumbá: AGB, 1996.

FABRINI, João Edmilson. A posse e a concentraçáo de terra no sul de Mato Grosso do Sul. In: ALMEIDA, Rosemeire Aparecida de. A questão Agrária em Mato Grosso do Sul: uma visão multidisciplinar. 1. ed. Campo Grande: UFMS, 2008, p. 53-80.

FERNANDES, Bernardo Mançano. MST: Espacialização e territorialização da luta pela terra: Movimento dos trabalhadores rurais sem terra - formação e territorialização em São Paulo.

207 f. Dissertação (Mestrado em Geografia), Faculdade de Filosofia, Letras e Ciências Humanas Departamento de geografia. Universidade de São Paulo - USP. São Paulo, 1994.

FERNANDES, Bernardo Mançano. Contribuiçáo ao estudo do campesinato brasileiro: Formação e territorialização do movimento dos trabalhadores rurais sem-terra - MST (1979- 1999). 316 f. Tese (Doutorado em Geografia) - Faculdade de Filosofia, Letras e Ciências Humanas - Departamento de geografia. Universidade de São Paulo - USP. São Paulo, 1999. 
FERNANDES, Bernardo Mançano. WELCH, Cliford Andrew. GONÇALVES, Elienai Constantino. Os usos da terra no Brasil: Debates sobre políticas fundiárias. São Paulo: cultura Acadêmica: Unesco, 2014.

FERNANDES, Bernardo Mançano. Questáo agrária: conflitualidade e desenvolvimento territorial. 2005. Disponível em: <http://www.geografia.fflch.usp.br>. Acesso em: 04 dez. 2019.

FERNANDES, Bernardo Mançano. Sobre a Tipologia de Territórios. In: SAQUET, M. A.; SPOSITO, E. S. (Org.). Territórios e territorialidades: teorias, processos e conflitos. São Paulo: Expressão Popular, 2009.

FELICIO, Jorge Munir. Contribuição ao Debate Paradigmático da Questão Agrária e do Capitalismo Agrário. 214 f. Tese (Doutorado em Geografia) - Universidade Estadual Paulista. Presidente Prudente, 2011.

MOURA, Daise Jesus; VICTOR, Fabiana Borges; CLEPS JUNIOR, João. As Açóes Políticas Dos Movimentos Sociais do Campo em Minas Gerais: Manifestaçôes da Luta pela Terra e seus Desdobramentos. In: Encontro Nacional de Geógrafos. Minas Gerais. 2012. Disponível em< http://eng2012.agb.org.br/ lista-de-artigos? download=869:eng-moura-victor\&start=520.

>. Acesso em: 15 dez. 2019.

MST - Movimento dos Trabalhadores Rurais Sem Terra. 25 anos de lutas e conquistas. Jornal Sem Terra, 2009. Disponível em: <http://antigo.mst.org.br/jornal/289/estados>. Acesso em: 9 jan. 2019.

MORENO, Gislaene. A apropriaçáo do território. In: MORENO, G.; HIGA, T. C. S. (Org.). Geografia de Mato Grosso: território, sociedade, ambiente. Cuiabá: Entrelinhas, 2005.

PEREIRA, Danilo Valentin. Estudo sobre as tipologias de manifestaçóes no campo paulista no período 2000-2011. 2012. 87 f. Monografia (Bacharelado em Geografia). Curso de Graduação em Geografia. Universidade Estadual Paulista, campus de Presidente Prudente, 2012.

SILVA, Tânia Paula da. As formas organizacionais de produçáo dos camponeses no município de Batayporã/MS. 160 f. Dissertação (Mestrado em Geografia). Faculdade de Ciência e Tecnologia, Universidade Estadual Paulista. Presidente Prudente, 2004.

SILVA, Anderson Antônio da; FERNANDES, Bernardo Mançano. Manifestaçóes: a arte de fazer política fazendo manifestaçóes, ocupaçóes e acampamentos no Brasil de 2007. In Cadernos Conflitos no Campo Brasil 2007. Goiânia: Comissão Pastoral da Terra, 2008. 